\title{
Wind forced low frequency variability of the East Australia Current
}

\author{
K. L. Hill, ${ }^{1,2}$ S. R. Rintoul, ${ }^{1,3,4}$ R. Coleman, ${ }^{1,2,4}$ and K. R. Ridgway ${ }^{1,3}$ \\ Received 7 December 2007; revised 19 February 2008; accepted 10 March 2008; published 23 April 2008.
}

[1] A 62 year record of temperature and salinity from a coastal station off southeast Australia shows a strong positive trend and quasi-decadal variability but the cause of the observed changes has not been explained. The temperature and salinity variations are highly correlated. The increase in temperature and salinity with time agrees closely with the mean meridional gradient of water properties along the continental slope, suggesting that changes in strength of the poleward extension of the East Australian Current are responsible for the observed variability. Interannual temperature and salinity changes are correlated $(\mathrm{r}=0.7)$ with basin-scale winds and with transport through the Tasman Sea estimated from Island Rule, with the changes at the western boundary lagging the wind forcing by three years. We conclude that the trend and decadal variability in the coastal temperature and salinity record reflect the response of the subtropical gyre and western boundary current to basin-scale wind forcing. Citation: Hill, K. L., S. R. Rintoul, R. Coleman, and K. R. Ridgway (2008), Wind forced low frequency variability of the East Australia Current, Geophys. Res. Lett., 35, L08602, doi:10.1029/2007GL032912.

\section{Introduction}

[2] The waters off the east coast of Tasmania have become warmer and saltier over the last 60 years (by $2.28^{\circ} \mathrm{C}$ and 0.36 psu per century equivalent [Ridgway, 2007]), as seen in the long time series of temperature and salinity measurements taken at the Maria Island Coast Station. Both temperature and salinity also show significant decadal variability. While temperature and salinity changes have been attributed to a strengthening of the poleward extension of the East Australian Current (EAC) [Ridgway, 2007], the dynamics driving such a change have not been fully explored.

[3] NCEP-1 reanalysis winds show a general increase in the wind stress curl in the South Pacific, and a marked increase in the southern hemisphere westerlies since 1948 [Cai, 2006]. Intensification of the westerlies is well documented from models, reanalysis and observations [Kushner et al., 2001, Thompson and Solomon, 2002] and has been related to a positive trend in the Southern Annular Mode (SAM). This trend in the SAM has been related to both anthropogenic warming [Kushner et al., 2001] and ozone

\footnotetext{
${ }^{1}$ CSIRO Marine and Atmospheric Research, Hobart, Tasmania, Australia.

${ }^{2}$ Centre for Marine Science, University of Tasmania, Hobart, Tasmania, Australia.

${ }^{3}$ Center for Australian Weather and Climate Research, Hobart, Tasmania, Australia.

${ }^{4}$ Antarctic Climate and Ecosystems CRC, Hobart, Tasmania, Australia.
}

Copyright 2008 by the American Geophysical Union. 0094-8276/08/2007GL032912 loss [Thompson and Solomon, 2002; Cai and Cowan, 2007].

[4] Evidence is also mounting of the impact of wind field changes on the circulation of the South Pacific. Sutton et al. [2005] and Roemmich et al. [2007] observed decadal (1990-2000) warming in the in the eastern Tasman Sea and spin up of the South Pacific Gyre, respectively. They suggest these changes are due to strengthened winds in the South Pacific which resulted in increased Ekman pumping. Cai [2006] used the Island Rule [Godfrey, 1989] to show the 50 -year trend in NCEP-1 winds would cause a spin-up of the southern hemisphere supergyre.

[5] Here we use in situ observations and atmospheric reanalysis data to demonstrate that the low-frequency temperature and salinity variability observed at the Maria Island station reflects changes in the position and strength of the subtropical gyre in response to changes in South Pacific winds. The study provides a dynamical connection between the observational work of Ridgway [2007] and the modeling study of Cai et al. [2005] and extends the relationships discussed by Roemmich et al. [2007] and Qiu and Chen [2006] from 12 to 60 years.

\section{Data and Method}

[6] The Maria Island Time Series (MITS) station is situated off the southeast coast of Tasmania at $42.6^{\circ} \mathrm{S}$, $148.23^{\circ} \mathrm{E}$. It is the longest high quality time series station in the Southern Hemisphere, running from 1944 to the present day. The station is located at the $50 \mathrm{~m}$ isobath, approximately $5 \mathrm{~km}$ from the edge of the narrow continental shelf. Monthly temperature, salinity and nutrients measurements are taken from the surface to 50 metres at 10 metre intervals. While most of the EAC separates near $30^{\circ} \mathrm{S}$ forming the Tasman Front, the remainder of the current continues southward to form the EAC Extension [Cresswell, 2000] (Figure 1a). The ribbon of warm water carried south by the EAC Extension lies over the upper continental slope, just offshore of Maria Island (Figures $1 \mathrm{~b}$ and 1c). Ridgway [2007] used satellite measurements of surface temperature to confirm that the MITS temperature record represented the temperature of the EAC Extension and was correlated with surface temperature over a broader region.

[7] The CSIRO Atlas of Regional Seas (CARS 2006a) and the $1 / 8$ degree CARS coastal (Coast8 2006) dataset [Ridgway et al., 2002; Ridgway and Dunn, 2003] were used to compare MITS data with the regional temperature and salinity climatology.

[8] Regional mean wind stress curl for the South Pacific, defined as the region $180-280^{\circ} \mathrm{E}, 20-50^{\circ} \mathrm{S}$, was calculated using NCEP-1 Reanalysis Winds [Kalnay et al., 1996; Kistler et al., 2001]. NCEP-1 starts in 1948 and spans almost the entire period of the MITS record. Trends in southern high latitude atmospheric pressure fields may be 


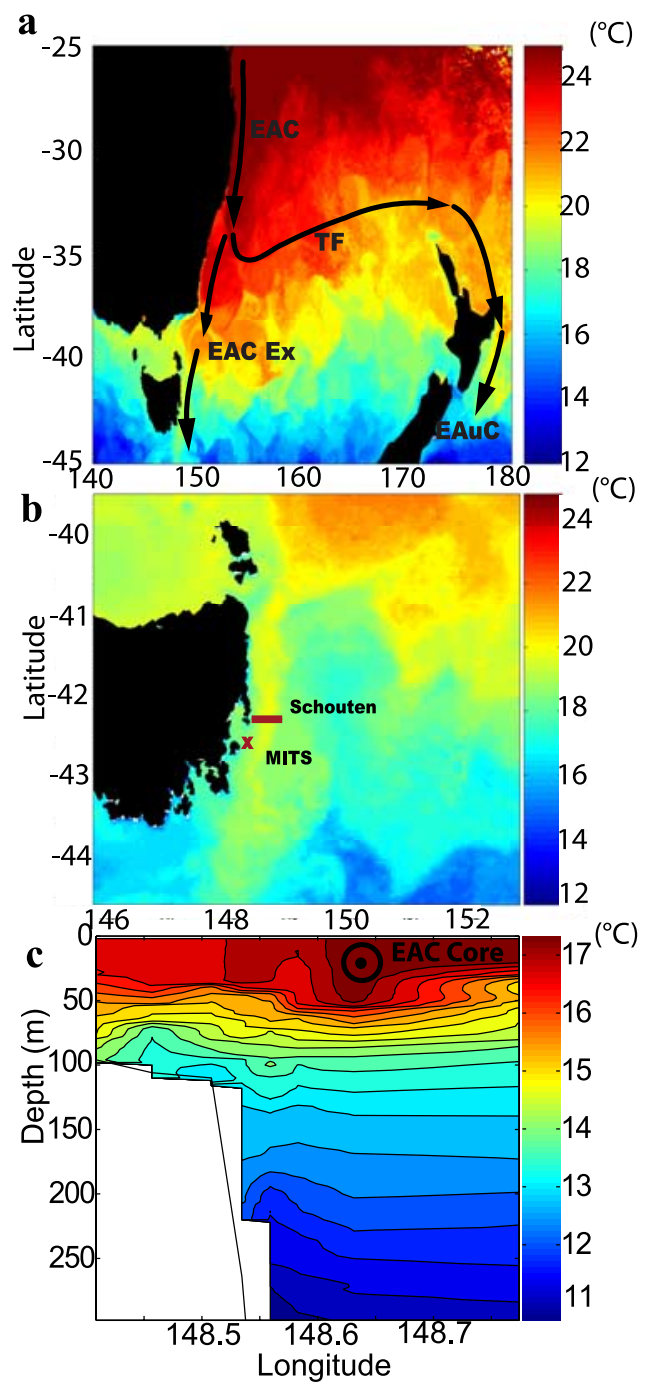

Figure 1. (a) Satellite SST of the Tasman Sea for March 2001. Superimposed are arrows showing the main regional currents. The East Australian Current (EAC), EAC Extension (EAC Ex) the Tasman Front (TF), and the East Auckland Current (EAuC). (b) Satellite SST of Tasmanian region. Locations of MITS (x) and the Schouten Island Transect (solid line). (c) A temperature transect offshore from Schouten Island [Cresswell, 2000]. Circle denotes EAC core.

suspect, particularly in higher latitudes, due to a lack of observations prior to the satellite era (pre 1978) [Kistler et al., 2001, Sturaro, 2003]. However, in situ observations also show a trend in southern hemisphere westerly wind strength, and a contraction towards the pole [e.g., Marshall, 2003; Bromwich and Fogt, 2004; Renwick, 2004; Tennant, 2004]. Here we consider the region north of $50^{\circ} \mathrm{S}$, where problems associated with the lack of high latitude observations is less severe.

[9] Transports through the Tasman Sea were calculated using the Island Rule [Godfrey, 1989]. The Tasman Sea transport was defined as the difference in Island Rule stream function for Australia and New Zealand. While this method produces a good approximation of the structure of the winddriven circulation, it has some limitations; first, the Island
Rule and Sverdrup balance describe the steady state response of the ocean circulation to Ekman pumping for periods longer than the circulation adjustment time. At subtropical latitudes, full baroclinic adjustment could take decades, so the Island Rule is unlikely to correctly capture the timing and amplitude of decadal variability. The Island Rule is also a linear approximation, so nonlinear dynamics of western boundary currents (e.g., retroflections and the details of the separation from the coast) are not represented. In addition, the results depend on the precise path taken to encompass the island and the western boundary when integrating the winds.

[10] All the time series were first low-pass filtered using a 5 -year running mean in order to focus on the low frequency variability. Time series were de-trended prior to performing cross-correlations.

\section{Results}

[11] Low-frequency changes in temperature and salinity at MITS strongly co-vary, with a trend over time from colder and fresher to warmer and saltier waters (Figure 2). The co-variation suggests that the observed changes are due to advection, rather than solar heating, evaporation/ precipitation or river runoff, which would cause one to vary without the other. The time evolution of temperature (T) - salinity (S) properties at MITS closely follows the climatological T/S relationship along the path of the EAC Extension, which shifts from cold, fresh waters in the south to warm, salty EAC waters in the north. The influence of the EAC relative to southern waters has increased markedly over time. The increase in temperature and salinity since 1944 corresponds to a southward shift of the climatological surface temperature and salinity properties by about three degrees of latitude.

[12] Comparison of the SST and salinity at MITS with regional mean wind stress curl in the South Pacific and transport through the Tasman Sea calculated using the Island Rule (Figure 3) suggests that changes at MITS can be related to changes in the regional mean wind stress curl over the South Pacific, and hence transport through the Tasman Sea. These time series all exhibit an upward trend, equivalent to $+0.22^{\circ} \mathrm{C}$, and $+0.03 \mathrm{psu},+0.34 * 10^{-8} \mathrm{Nm}^{-2}$, and +2.0 Sv change per decade for temperature, salinity, wind stress curl and transport, respectively. (A small difference in temperature and salinity trends between this study and Ridgway's [2007] results from the longer MITS dataset used here.) Each of the time series also show similar variability on decadal timescales. Sea surface temperature and salinity at MITS lag the basin-average wind stress curl by about three years.

[13] To test the hypothesis that changes in the wind stress curl drive the changes observed in MITS, the lagged cross-correlation was calculated between SST at MITS and wind stress curl averaged over the South Pacific and transport through the Tasman Sea. The maximum cross-correlations occur when MITS lags both the wind field and the Island rule transports by $\sim 3$ years, with a correlation of $r=0.7$. The lag between transport and $\mathrm{T} / \mathrm{S}$ at MITS likely reflects the inadequacies of the Island Rule assumption of an instantaneous response to winds. 


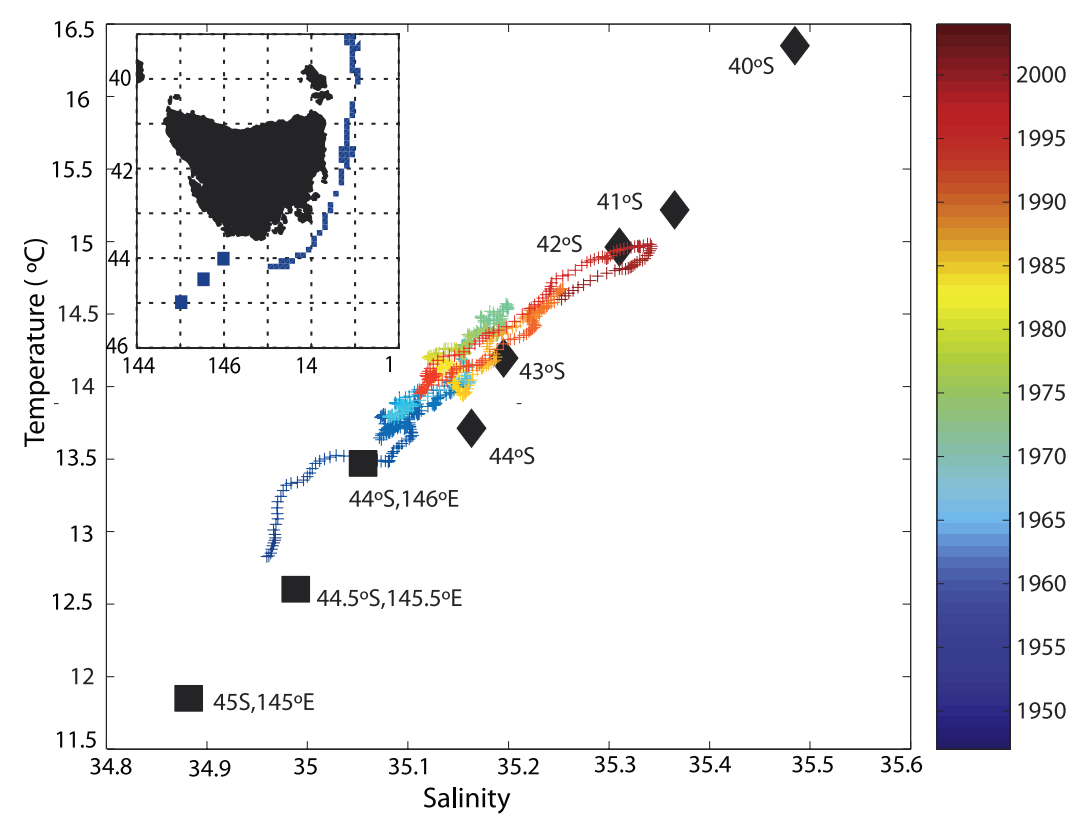

Figure 2. The colored symbols indicate the low-pass filtered surface temperature and salinity data from MITS as a function of time, with colors corresponding to dates on the color bar. The diamonds represent the mean surface T/S relationship along the continental slope between the 500 and $1500 \mathrm{~m}$ isobaths from the coastal CARS atlas (blue areas on map), averaged over \pm 0.5 degrees from the specified latitudes. The squares represent the colder/fresher surface climatological temperature and salinity endpoint from the CARS Atlas, at the specified latitudes and longitudes south and west of MITS (blue squares on map).

[14] The spatial pattern of the 3-year lag correlation between MITS SST and winds shows high correlation $(\mathrm{r}=$ 0.4-0.8) over much of the South Pacific basin (Figure 4). The highest correlations are found in the southern part of the basin, east of New Zealand. The black contours show the time taken for first mode baroclinic Rossby waves to reach the western boundary. It would take 10 years for Rossby waves to transit the South Pacific Basin at $30^{\circ} \mathrm{S}$, and $15-$ 20 years at $42.5^{\circ} \mathrm{S}$. The areas of high correlation with MITS SST lie well to the east of the line marking the distance from

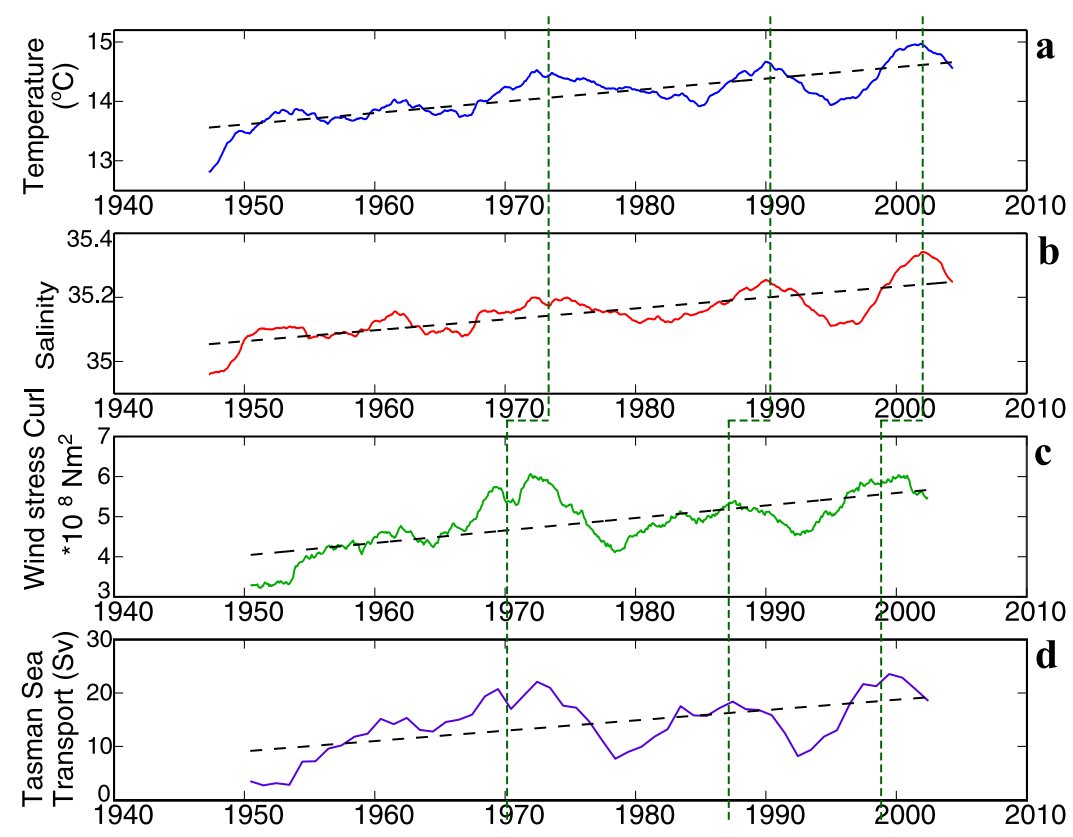

Figure 3. Low-pass filtered (a) sea surface temperature at MITS, (b) surface salinity at MITS, (c) South Pacific regional mean wind stress curl $\left(20-50^{\circ} \mathrm{S}, 180-280^{\circ} \mathrm{E}\right)$, (d) net transport through the Tasman Sea, calculated using the Island Rule [Godfrey, 1989]. Black dashed lines show the linear trend. Green dashed lines illustrate the time lag between MITS T/S and South Pacific winds/Island rule transports. 


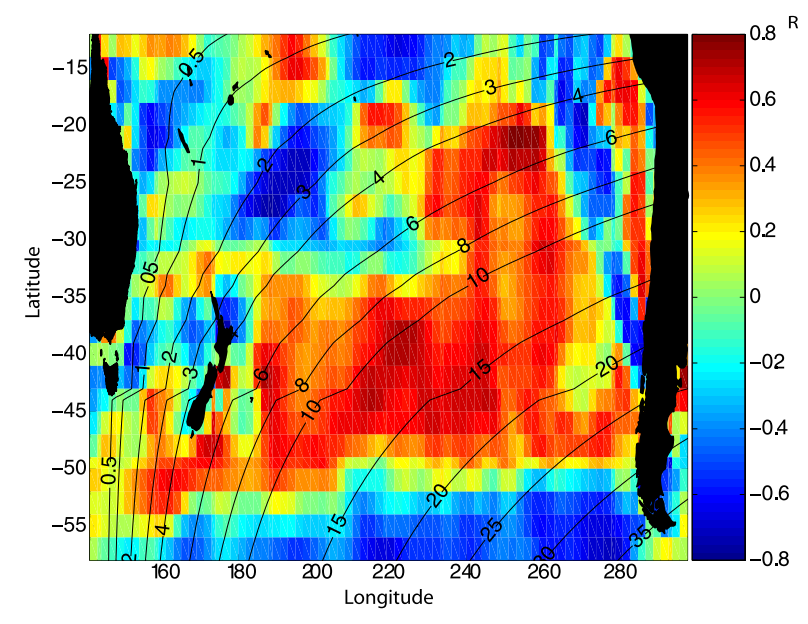

Figure 4. Spatial pattern of the 3-year lagged crosscorrelation between surface temperature at MITS and wind stress curl. Contours are the time (years) required for long baroclinic Rossby to reach the East Coast of Australia. Rossby wave speeds $C_{R}=\beta / C_{1}^{2} / \mathrm{f}^{2}$ where gravity wave speed, $\mathrm{C}_{1}=3$ [Chelton et al., 1998], $\mathrm{f}$ is the Coriolis parameter and $\beta$ is the meridional variation of the Coriolis parameter.

which a first mode baroclinic Rossby wave can reach the western boundary within three years.

\section{Discussion}

[15] Comparison of the time series of temperature and salinity variations at Maria Island to the climatological T-S properties along the continental slope suggests that changes in the amount of EAC water extending to the south can explain the trend and quasi-decadal variability in the MITS record. Changes in the southward extension of the EAC are, in turn, linked to changes in wind stress curl over a broad region of the South Pacific.

[16] Ridgway [2007] discussed the 60 year trend in temperature and salinity observed at MITS and related the changes to stronger southward penetration of warm saline EAC waters with time. Cai [2006] used a simple Island Rule model to show that the change in Southern Hemisphere winds over the past 50 years would cause a spin up of the Southern Hemisphere super-gyre, consistent with a stronger EAC extension. We demonstrate the link between basin-scale changes in wind forcing and low frequency variability of the EAC, providing a bridge between those earlier studies of the trend at MITS, and the trend in the South Pacific winds. We also document strong decadal variability at MITS and show that the relationship between basin - scale wind forcing, transport and temperature and salinity observations at the western boundary holds on decadal timescales as well.

[17] The Island Rule [Godfrey, 1989] solution calculated from the NCEP-1 winds suggests that transport through the Tasman Sea has intensified by almost a factor of two between 1948 and 2001. The low frequency variability of transport is also similar to that of temperature and salinity at MITS. However transports calculated using the Island Rule are large at 10-20 Sv compared to a mean observed transport of $9.4 \mathrm{~Sv}$ from observations [Ridgway and Godfrey, 1994]. This could be related to non-linear features such as the separation zone, or bathymetric features not being represented. Also, calculated transports through the Tasman Sea lead the observed T/S change by the same time frame as the winds. This may reflect the Island Rule assumption of an instantaneous response to changes in wind forcing.

[18] Decadal changes in the strength of the South Pacific Gyre have been discussed by Roemmich et al. [2007] and Qiu and Chen [2006] using 12 years of data. Both papers identified a tendency towards a stronger gyre in the 1990 s with a reversal of sign in the early 2000s. The phase of this pattern fits with the last peak in the time series of MITS, wind stress curl and transport (Figure 3). The earlier studies relied on the short period of satellite altimeter data and so could not determine the time-scale of variability of the gyre. The 60 year record analyzed here shows clear evidence of both a trend and significant decadal variability in the strength of the South Pacific Gyre.

[19] Both Roemmich et al. [2007] and Qiu and Chen [2006] suggested that the changes they observed in the gyre reflected changes in the South Pacific winds a few years earlier. The short records they considered made it difficult to clearly resolve the time-scale of the lag between wind forcing and response, and the relative importance of propagating baroclinic waves and local Ekman pumping remained unclear. We find the strongest correlation between the Maria and basin-scale winds occurs at about three years. The areas of strongest correlation (Figure 4) are too far east for first mode baroclinic Rossby waves to reach the western boundary within three years. The relative role of local forcing and propagating waves (baroclinic and barotropic) in determining the response of the subtropical gyre to changes in winds will be the topic of further work.

[20] Changes in the range of species across a number of marine taxa have been related to changes in the strength of the EAC [Edgar, 2000; Thresher et al., 2003]. An assessment of the potential impact of climate change on marine life in Australia [Poloczanska et al., 2007] concludes the projected strengthening EAC and continued warming of the south Tasman Sea will have a detrimental effect on coldtemperate species in South East Australia, particularly in Tasmanian waters. Such ecosystem shifts will also impact on commercially important fisheries such as abalone and rock lobster. Our results suggest that observed ecosystem changes are likely linked to changes in ocean circulation driven by changes in basin-scale winds. Strategies for management of marine resources in southeastern Australia will need to take into account the response of regional oceanographic conditions to climate variability and change.

\section{References}

Bromwich, D. L., and R. L. Fogt (2004), Strong trends in the skill of the ERA-40 and NCEP-NCAR reanalyses in the high and midlatitudes of the Southern Hemisphere, J. Clim., 17(23), 4603-4619.

Cai, W. (2006), Antarctic ozone depletion causes an intensification of the Southern Ocean super-gyre circulation, Geophys. Res. Lett., 33, L03712, doi:10.1029/2005GL024911.

Cai, W., and T. Cowan (2007), Trends in the southern hemisphere circulation in IPCC AR4 models over 1950-1999: Ozone depletion verses greenhouse forcing, J. Clim., 20, 681-693.

Cai, W., G. Shi, T. Cowan, D. Bi, and J. Ribbe (2005), The response of the Southern Annular Mode, the East Australian Current, and the southern mid-latitude ocean circulation to global warming, Geophys. Res. Lett., 32, L23706, doi:10.1029/2005GL024701. 
Chelton, D. B., R. A. deSzoeke, M. G. Schlax, K. El Naggar, and N. Siwertz (1998), Geographical variability of the first baroclinic Rossby radius of deformation, J. Phys. Oceanogr., 28, 433-460.

Cresswell, G. R. (2000), Currents of the continental shelf and upper slope of Tasmania, Pap. Proc. R. Soc. Tasmania, 133, 21-30.

Edgar, G. J. (2000), Australian Marine Life: The Plants and Animals of Temperate Waters, rev. ed., Reed New Holland, Sydney, Australia.

Godfrey, J. S. (1989), A Sverdrup model of the depth integrated flow for the world ocean allowing for island calculations, Geophys. Astrophys. Fluid Dyn., 45, 89-112.

Kalnay, E., et al. (1996), The NCEP/NCAR 40-year reanalysis project, Bull. Am. Meteorol. Soc., 77, 347-471.

Kistler, R., et al. (2001), NCEP-NCAR 50 year reanalysis: Monthly means CD-ROM and documentation, Bull. Am. Meteorol. Soc., 82, 247-267.

Kushner, P. J., I. M. Held, and T. L. Delworth (2001), Southern Hemisphere atmospheric circulation respnse to global warming, J. Clim., 14, 2238-2246.

Marshall, G. J. (2003), Trends in the Southern Annular Mode from Observations and Reanalysis, J. Clim., 16, 4134-4143.

Poloczanska, E. S., R. C. Babcock, A. Butler, A. J. Hobday, O. Hoegh-Guldberg, T. J. Kunz, R. Matear, D. Milton, T. A. Okey, and A. J. Richardson (2007), Climate change and Australian marine life, Oceanogr. Mar. Biol. Annu. Rev., 45, 407-478.

Qiu, B., and S. Chen (2006), Decadal variability in the large-scale sea surface height field of the South Pacific Ocean: Observations and causes, J. Phys. Oceanogr., 36(9), 1751-1762.

Renwick, J. A. (2004), Trends in the Southern Hemisphere polar vortex in NCEP and ECMWF reanalyses, Geophys. Res. Lett., 31, L07209, doi:10.1029/2003GL019302.

Ridgway, K. R. (2007), Long-term trend and decadal variability of the southward penetration of the East Australian Current, Geophys. Res. Lett., 34, L13613, doi:10.1029/2007GL030393.
Ridgway, K. R., and J. R. Dunn (2003), Mesoscale structure of the East Australian Current system and its relationship with topography, Progr. Oceanogr., 56, 189-222.

Ridgway, K. R., and J. S. Godfrey (1994), Mass and heat budgets in the East Australian Current: A direct approach, J. Geophys. Res., 99, $3231-3248$.

Ridgway, K. R., J. R. Dunn, and J. L. Wilkin (2002), Ocean interpolation by 4-dimensional weighted least squares-Application to the waters around Australasia, J. Atmos. Oceanic Technol., 19, 1357-1375.

Roemmich, D., J. Gilson, R. Davies, P. Sutton, S. Wijffels, and S. Riser (2007), Decadal spin up of the deep subtropical gyre in the South Pacific, J. Phys. Oceanogr., 37, 162-173.

Sturaro, G. (2003), A closer look at the climatological discontinuities present in the NCEP/NCAR reanalysis temperature due to the introduction of satellite data, Clim.e Dyn., 21, 309-316.

Sutton, P., M. Bowen, and D. Roemmich (2005), Decadal temperature changes in the Tasman Sea, N. Z. J. Mar. Freshwater Res., 39, $1321-1329$.

Tennant, W. (2004), Considerations when using pre-1979 NCEP/NCAR reanalyses in the southern hemisphere, Geophys. Res. Lett., 31, L11112, doi:10.1029/2004GL019751.

Thompson, D. W. J., and S. Solomon (2002), Interpretation of recent Southern Hemisphere climate change, Science, 296, 895-899.

Thresher, R., C. Proctor, G. Ruiz, R. Gurney, C. MacKinnon, W. Walton, L. Rodriguez, and N. Bax (2003), Invasion dynamics of the European shore crab, Carcinus maenas, in Australia, Mar. Biol., 142, 867-876.

K. L. Hill, K. R. Ridgway, and S. R. Rintoul, CSIRO Marine and Atmospheric Research, GPO Box 1538, Hobart, Tas 7001 Australia. (katy.hill@csiro.au)

R. Coleman, Centre for Marine Science, University of Tasmania, Hobart, Tas 7001 Australia. 